www.jmscr.igmpublication.org

Index Copernicus Value: 79.54

ISSN (e)-2347-176x ISSN (p) 2455-0450

crossref DOI: https://dx.doi.org/10.18535/jmscr/v7i4.186

\title{
Bode Index in COPD Patients during Acute Exacerbations and its Influence on Treatment Outcome - An Observational Study
}

\author{
Authors \\ Dr Durga Balagopalan, Dr Ponneduthamkuzhy Thomas. James, \\ Dr Anoop Muthiraparambathu \\ ${ }^{1}$ Assistant Professor Malabar Medical College Kozhikode \\ ${ }^{2}$ HOD Amrita Institute of Medical Sciences, Kochi \\ ${ }^{3}$ Senior Consultant Aster MIMS Kozhikode
}

\begin{abstract}
Background: Exacerbations of COPD can range from those that are nuisances to those that are life threatening, but treatment can shorten the duration of illness and improve outcomes.

So this study intended to find out the mortality rate in patients with COPD acute exacerbations and also to find out simple clinical and laboratory parameters that may predict the mortality in these patients and also influence of $B O D E$ Index on the treatment outcome of COPD exacerbations.

Objective: To find out the influence of BODE index in the treatment outcome of COPD during acute exacerbation.

Materials and Methods: This study was an observational study. All cases of COPD diagnosed by a physician and on treatment for more than one year, admitted in Institute of Chest Diseases with exacerbation were included in the study. BODE Index was calculated.

Data were collected and tabulated. Statistical analysis was done using SPSS Software version 12.0 and Epi Info version 3.4 .1

Results: This study gives a brief idea about the mortality rate in COPD acute exacerbations.. All the patients were males. 34 patients died during treatment. In the study, most of the patients belong to the age group between $60-70$ years. BODE score $>7$ was found to be a predictor of mortality in these patients by univariate analysis ( $p$ value $=0.036)$. But there was no statistical significance with multivariate analysis for this observation.

Conclusion: Mortality rate of COPD acute exacerbations was $33.66 \%$ in this observational study. BODE score $>7$ was found to be a predictor of mortality in COPD acute exacerbations by univariate analysis.
\end{abstract}

\section{Introduction}

COPD is a preventable and treatable disease with some significant extra pulmonary effects that may contribute to the severity in individual patients. Its pulmonary components are characterized by airflow limitation that is not fully reversible. The airflow limitation is usually progressive and associated with an abnormal inflammatory response ${ }^{1}$.
COPD is a major cause of chronic morbidity and mortality thought out the world and results in an economic and social burden that is both substantial and increasing ${ }^{1,2}$. Currently, COPD is a more costly disease than asthma and, depending on country, 50 to 75 percent of the costs are for services associated with exacerbations ${ }^{2}$.

A complex and interrelated set of risk factors influences functional decline, exacerbation and early mortality in patients with COPD. With 
limited health care resources, efficient and effective management of COPD ideally involves identifying and focusing efforts on individuals who are at particular risk ${ }^{1}$.

Exacerbations of COPD can range from those that are nuisances to those that are life threatening, but treatment can shorten the duration of illness and improve outcomes ${ }^{3}$.

So this study intended to find out the mortality rate in patients with COPD acute exacerbations and also to find out simple clinical and laboratory parameters that may predict the mortality in these patients. We tried to find out the influence of a multidimensional grading system, BODE score that assessed the respiratory and systemic expressions of COPD on treatment outcome of COPD during acute exacerbations.

\section{Aim}

To find out the influence of BODE index in the treatment outcome of COPD during acute exacerbation

\section{Background of the Study}

Chronic obstructive pulmonary disease (COPD) ranks fourth as a cause of death in the United States, behind heart disease, cancer, and stroke. Additionally, since serious co-morbidities are often present in patients with COPD, many die from other diseases such as cardiac disease or cancer. Not surprisingly, multiple factors, reflective of both respiratory disease process and the substantial co-morbidity, predict survival in the disease ${ }^{3}$.

\section{Materials and Methods}

This study was an observational study. All cases of COPD diagnosed by a physician and on treatment for more than one year, admitted in Institute of Chest Diseases with exacerbation were included in the study.

\section{Exclusion Criteria}

Patients with co morbid conditions like

- Primary heart Disease

- Cirrhosis Liver
- Immunodeficiency

- Renal failure

\section{Methodology}

Patients enrolled in to the study were evaluated in detail by

\section{I) A detailed history including}

1. Age

2. Sex

3. BODE index ${ }^{7}$

a) Body mass index

b) Airflow obstruction as by FEV1

c) MMRC grading of Dyspnea

d) Exercise capacity (6 minute Walk test)

4. Number of days in the hospital

5. Cause of present exacerbation whether infective or non-infective

\section{Statistical Analysis}

Data were collected and tabulated. Statistical analysis was done using SPSS Software version 12.0 and Epi Info version 3.4.1. Univariate analysis comparing various variables in survivors and non survivors was done using Chi Square test and $p$ value and Odds ratio were calculated. Then multivariate analysis was done using linear regression analysis to find out the most important independent predictors of mortality in COPD acute exacerbations.

Study was approved by institutional ethics committee.

\section{Results}

This study gives a brief idea about the mortality rate in COPD acute exacerbations.

In this observational study 101 patients admitted with COPD acute exacerbations were considered. All the patients were males. Death was considered as poor outcome. 34 patients died during treatment (graph 1). 


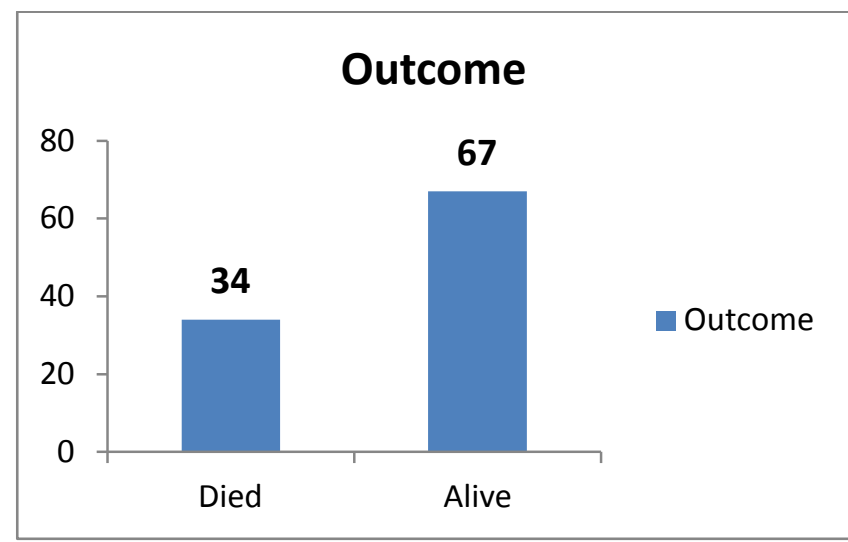

Graph 1

In the study mean age of patients was 62.33 years and most of the patients belong to the age group between $60-70$ years (graph 2).

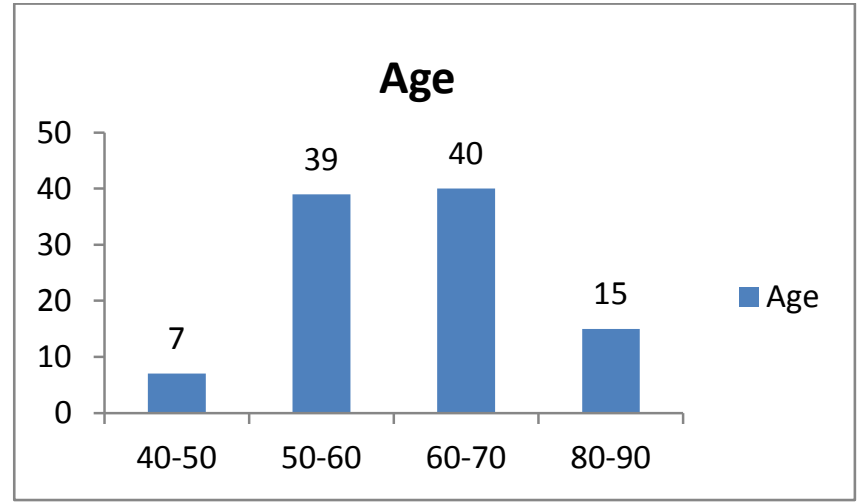

\section{Graph 2}

On examination 69 patients had a Body Mass Index (BMI) of <21 (graph 3).0f which 21 patients had a poor outcome (graph 4).32 patients who died had a BODE score greater than seven (graph5). BODE score $>7$ was found to be a predictor of mortality in these patients by univariate analysis ( $\mathrm{p}$ value $=0.036$ ) table 1.But there was no statistical significance with multivariate analysis for this observation (table 2)

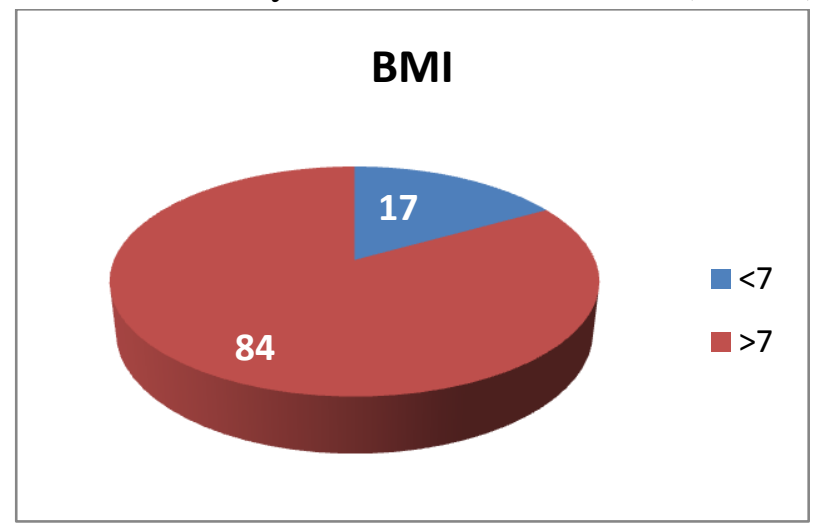

Graph 3

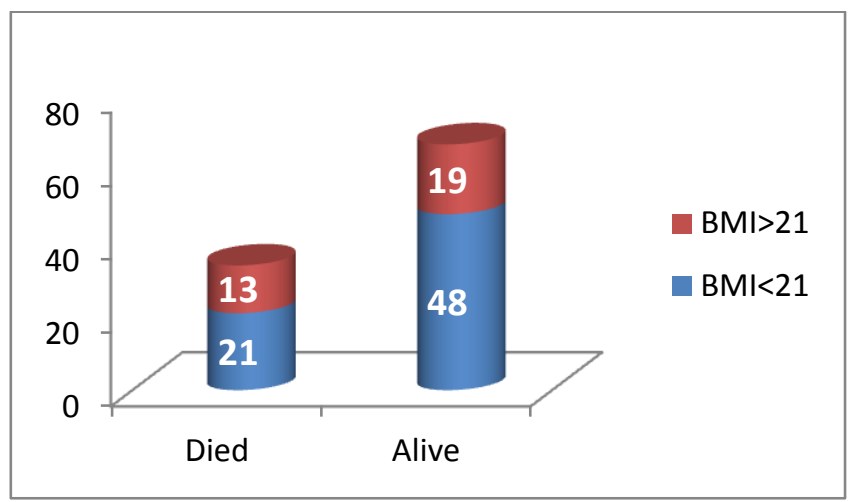

Graph 4

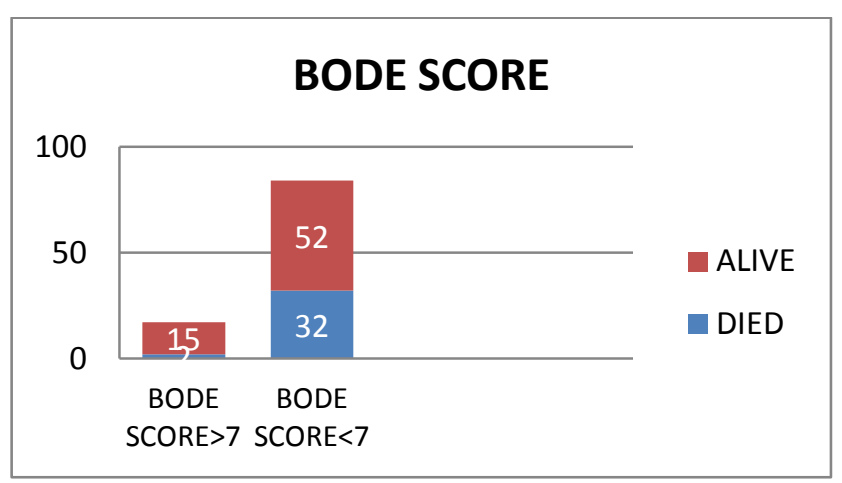

Graph 5

Table 1

\begin{tabular}{|c|c|c|c|}
\hline \multicolumn{4}{|c|}{ Risk Estimate } \\
\hline & \multirow[b]{2}{*}{ Value } & \multicolumn{2}{|c|}{$\begin{array}{c}95 \% \text { Confidence } \\
\text { Interval }\end{array}$} \\
\hline & & Low er & Upper \\
\hline $\begin{array}{l}\text { Odds Ratio for } \\
\text { Outcome (Died / Alive) }\end{array}$ & 4.615 & .990 & 21.523 \\
\hline $\begin{array}{l}\text { For cohort BODEsco_ } \\
\text { grp }=>=7\end{array}$ & 1.213 & 1.040 & 1.414 \\
\hline $\begin{array}{l}\text { For cohort BODEsco_ } \\
\text { grp }=<7\end{array}$ & .263 & .064 & 1.083 \\
\hline Nof Valid Cases & 101 & & \\
\hline
\end{tabular}

Table 2

\begin{tabular}{|l|c|c|c|c|}
\hline Variable & Coefficient & $\begin{array}{c}\text { Std } \\
\text { Error }\end{array}$ & F-test & P-Value \\
\hline $\begin{array}{l}\text { BODE } \\
\text { score }\end{array}$ & 0.008 & 0.039 & 0.0473 & 0.828288 \\
\hline
\end{tabular}

Correlation Coefficient: $\mathrm{r}^{\wedge} 20.43$

\section{Discussion}

In this study 101 patients admitted with COPD acute exacerbations were taken into consideration. All the patients were males. Death was considered as the poor outcome. We tried to find out important predictors of mortality in patients during COPD acute exacerbations.34 (33.66\%) 
patients died during treatment and 67(66.34\%) survived the acute event.3 patients were mechanically ventilated. All the three patients expired.

UcqunI et al found out a similar in hospital mortality rate $(33.1 \%)$ for patients admitted with COPD acute hypercapnic respiratory failure in their study ${ }^{4}$. Susheel Patil et al mentioned in their study that previous studies of selected populations of patients with COPD have estimated in-hospital mortality to range from $4 \%$ to $30 \% 5$.

Demographics

In our study mean age was 62.33 and most of the patients belonged to the age group between 6070years (39.60\%). 39(38.61\%) patients belonged to the age group of $50-60$ years. Divay Chandra et al found almost similar age group of patients in a similar study conducted by them; ie, the mean age was 61.2 years ${ }^{6}$.

\section{Physical Examination}

$69(68.32 \%)$ of 101 patients had a Body Mass Index (BMI) of $<21.32(31.68 \%)$ patients had a BMI of $>21$.Even though 21(61.76\%) patients of 34 patients who died had $\mathrm{BMI}<21$ it was not a significant predictor of mortality in my study by statistical analysis. This observation may be due to small size of study group.

But S.Marti et al had concluded in his study that body mass index $<25 \mathrm{~kg} \cdot \mathrm{m}^{-2}$ and co morbidity were predictors of all-cause and respiratory mortality in a cohort of chronic obstructive pulmonary disease patients treated with long-term oxygen therapy. These factors should be taken into account when considering the management and prognosis of these patient ${ }^{7}$. Connors et al also found low BMI as an important predictor of mortality in COPD exacerbations ${ }^{8}$.

\section{BODE Score}

32(94.12\%) patients who died had a BODE score greater than seven. BODE score $>7$ was found to be a predictor of mortality in these patients by univariate analysis ( $\mathrm{p}$ value $=0.036$ ) table 1 . But there was no statistical significance with multivariate analysis for this observation table
7.Various studies showed BODE score system as an important predictor of poor outcome in COPD patients. R.Celli et al found out that the BODE index, a simple multidimensional grading system, is better than the $\mathrm{FEV}_{1}$ at predicting the risk of death from any cause and from respiratory causes among patients with COPD ${ }^{9}$. Fernando J Martinez et al mentioned in their study that when used in place of its components a higher modified BODE index predicted mortality ${ }^{10}$.

\section{Conclusion}

Majority of the patients in the study belonged to the age group between $60-70$ yrs.

Mortality rate of COPD acute exacerbations was $33.66 \%$ in this observational study.

BODE score $>7$ wasfound to bea predictor of mortality in COPD acute exacerbations by univariate analysis. But there was no statistically significance in multivariate analysis. BODE Index was a better predictor of mortality during acute exacerbation of COPD than BMI alone.

\section{References}

1. Global Strategy For Diagnosis, Management, And Prevention Of Chronic Obstructive Pulmonary Disease, 2019

2. ATS/ERS Summary: Standards for the diagnosis and treatment of patients with COPD

3. Fishman's Pulmonary Diseases and Disorders Fourth Edition p 691- 931

4. Predictors of hospital outcome and intubation in COPD patients admitted to respiratory icu for acute hypercapnic respiratory failure Ucqun 1, Metintas $\mathrm{M}$, Moral H, Alatas F, Yildrim H, Erqinel S; Department of chest diseases medical faculty Osmangazi university, $\operatorname{Tr} 26040$ Eskisehir Turkey; Respir Med 2006 Jan, 100(1);66-74

5. Divay Chandra, Kalpalatha K. Guntupalli and Randeep Guleria Departments of Internal Medicine and Pulmonary Medicine, All India Institute of Medical 
Sciences, New Delhi, India and Department of Pulmonary and Critical Care Medicine, Baylor College of Medicine, Houston, Texas, USA ;Indian J Chest Dis Allied Sci 2007; 49: 13-18

6. In-Hospital Mortality Following Acute Exacerbations of Chronic Obstructive Pulmonary Disease Susheel P. Patil, MD; Jerry A. Krishnan, MD; Noah Lechtzin, MD, MHS; Gregory B. Diette, MD, MHS; Arch Intern Med. 2003;163:1180-1186.

7. Body weight and comorbidity predict mortality in COPD patients treated with oxygen therapy ; S. Marti, X. Muñoz, J. Rios, F.Morell and J.Ferrer Servei de Pneumologia, Hospital General Vall d'Hebron, and Laboratori de Bioestadística i Epidemiologia, Universtitat Autònoma de Barcelona, Barcelona, Spain; Eur Respir J 2006; 27:689-696.
8. Management of Acute Exacerbations of COPD A Summary and Appraisal of Published Evidence; Douglas C. McCrory, MD, MHSc, Cynthia Brown, MD, Sarah E. Gelfand, BA, and Peter B. Bach, MD CHEST April 2001 vol. 119 no. 4 11901209

9. Bartlome. R..Celli, M.D and et al; Body Mass Index, Airflow Obstruction, Dysnoea and Exercise capacity Index in Chronic Obstructive Pulmonary Diseases; The NEJM Volume 350:1005 - 1012, March 4 2004.

10. Predictors of Mortality in Patients with Emphysema and Severe Airflow Obstruction; Fernando J Martinez*, Gregory Foster, Jeffrey L Curtis, Gerard Criner Gail Weinmann, Alfred Fishman, Malcolm M DeCamp, Joshua Benditt, Frank Sciurba, Barry Make, Zab Mohsenifar $^{1}$ 